\title{
Is it safe to use intravenous iron sucrose during pregnancy? A randomized controlled trial
}

\author{
Sunita Dubey $^{1}{ }^{*}, \operatorname{Vanita}_{\text {Suri }}{ }^{1}$, Neelam Aggarawal ${ }^{1}$, Reena Das ${ }^{2}$
}

\begin{abstract}
${ }^{1}$ Department of Obstetrics and Gynecology, ${ }^{2}$ Department of Hematology, Postgraduate Institute of Medical Education and Research, Sector 12, Chandigarh-160012, India
\end{abstract}

Received: 18 September 2013

Accepted: 5 October 2013

\section{*Correspondence:}

Dr. Sunita Dubey,

E-mail: sunitas504@gmail.com

(C) 2013 Dubey S et al. This is an open-access article distributed under the terms of the Creative Commons Attribution Non-Commercial License, which permits unrestricted non-commercial use, distribution, and reproduction in any medium, provided the original work is properly cited.

\begin{abstract}
Background: To compare the efficacy and safety of intravenous iron sucrose to oral iron in the treatment of iron deficiency anemia in pregnancy.

Methods: In this randomized trial 200 pregnant women with hemoglobin between $7 \mathrm{~g} / \mathrm{dl}$ and $9 \mathrm{~g} / \mathrm{dl}$ and serum ferritin $<15 \mathrm{ng} / \mathrm{ml}$ received either iron sucrose or oral iron sulphate. The iron sucrose dose was calculated from the following formula: weight $(\mathrm{kg}) \times(110 \mathrm{~g} / \mathrm{l}-$ actual hemoglobin $(\mathrm{g} / \mathrm{l}) \times 0.24+500 \mathrm{mg}$. Treatment efficacy was assessed by clinical and laboratory response on $2^{\text {nd }}$ week, $4^{\text {th }}$ week of therapy, after that $4^{\text {th }}$ weekly till delivery. Statistical analysis was done with paired and independent samples " $t$ " test applied. Hemoglobin measurements were analyzed by repeated- measures of analysis of variance with Huynh and Feldt corrections. Serum ferritin measurement across the time within each group was analyzed by two sample test with equal variance .Adverse drug reactions, fetal weight, blood transfusions were also recorded.

Results: The significant rise in hemoglobin from $8.0 \pm 0.79 \mathrm{gm} / \mathrm{dl}$ to $10.80 \pm 0.61 \mathrm{gm} / \mathrm{dl}$ in intravenous group as compared to oral iron group from $8.19 \pm 0.60 \mathrm{gm} / \mathrm{dl}$ to $9.86 \pm 0.61 \mathrm{gm} / \mathrm{dl}$ was seen at $4^{\text {th }}$ week of treatment $(P=0.000)$. After 2 week of treatment rise in serum ferritin values were higher in intravenous group from $6.25 \pm 1.05 \mathrm{ng} / \mathrm{ml}$; to $155.33 \pm 57.4 \mathrm{ng} / \mathrm{ml}$ and in oral group from $5.71 \pm 1.71 \mathrm{ng} / \mathrm{ml}$ to $20.8 \pm 9.5 \mathrm{ng} / \mathrm{ml} \mathrm{(} \mathrm{p}=.000$ ). No serious adverse drug reactions were observed in intravenous group.

Conclusion: Iron sucrose is safe to use during pregnancy. It raises hemoglobin and restores iron stores faster than oral iron.
\end{abstract}

Keywords: Anemia, Iron deficiency anemia, Intravenous iron therapy, Iron sucrose, Serum ferritin

\section{INTRODUCTION}

Iron deficiency anemia is the most common nutritional disorder in the world, affecting approximately $25 \%$ of the world's population. ${ }^{1}$ The prevalence of iron deficiency anemia in pregnant women is estimated to be $35 \%-75 \%$ (average 56\%) in developing countries where as in industrialized countries the average prevalence is $18 \% .^{2,3}$ Anemia during pregnancy has been shown to be associated with two fold risk of preterm delivery ${ }^{4}$ and three-fold risk for low birth-weight as well as maternal mortality. ${ }^{5}$ The World Health Organization (WHO) estimates that anemia contributed to approximately $20 \%$ of the 515,000 maternal deaths worldwide in $1995 .^{6}$

According to recent studies, the prevalence of iron deficiency anemia in first trimester ranges from $3.5 \%$ $7.4 \%$ and increases to $15.6 \%-55 \%$ in third trimester. ${ }^{7}$ With adequate iron stores, daily iron requirement increases from an average of $2 \mathrm{mg}-3 \mathrm{mg} /$ day in early trimester to $6 \mathrm{mg}-8 \mathrm{mg} /$ day in the last trimester which is explained by hemodilution phenomenon. ${ }^{8}$ 
Oral iron is the treatment of choice because of its effectiveness, safety and low cost. Parenteral iron is reserved for those in whom oral treatment fails due side effects, noncompliance, decreased absorption like ulcerative colitis and last trimester of pregnancy when rapid correction of anemia is needed.

As compared with oral iron, IM iron dextran injections are painful with risk of skin staining. However, intravenous iron dextran induces similar or slightly more rapid erythropoietic response than oral iron. ${ }^{9}$ The advantage of IM iron dextran is that, it can be administered in primary care after test dose, although facilities for resuscitation should be available as there is a small risk of allergic and anaphylaxis reaction.

Iron sucrose is a complex of polynuclear iron III hydroxide in sucrose for intravenous use. The polynuclear iron III - hydroxide cores are superficially surrounded by a large number of noncovalently bound sucrose molecules resulting in a complex with a molecular weight of approximately 60000 Daltons. The Iron in the polynuclear cores is bound in a similar structure to that of physiological condition. Its i.v. route makes availability of elemental iron for incorporation at the pro-erythroblast stage and hence it can provide quick rise in $\mathrm{Hb}$ within 5 to 7 days. The short half life of 5-6 hrs is responsible for rapid erythropoiesis as compared to iron dextran; which has serum half life of 3-4 days. ${ }^{10}$ Rate of iron delivery is a major factor in the regulation of marrow proliferation ${ }^{11}$ so it produces a more rapid increase in hemoglobin concentration than oral iron and iron dextran. ${ }^{12}$ It is administered without a test dose ${ }^{13}$ and have lower incidence of allergic reactions. Death from anaphylactic reactions has not been reported till date with its use. $^{14}$

Iron III carboxymaltose and Iron III isomaltose are new intravenous iron preparations which have advantage of giving large amount in single dose but data's are not available regarding their use in pregnancy.

Few studies ${ }^{15-19}$ have compared efficacy and safety of intravenous iron sucrose with oral iron during pregnancy. A recent Cochrane review ${ }^{20}$ on treatments for iron deficiency in anemia highlighted the need for good quality randomized controlled trials in this setting, in particular to assess clinical outcomes and adverse events. This study was conducted due to lack of quality trials regarding its safety and efficacy.

\section{METHODS}

This study was carried out in the Department of Obstetrics and Hematology, Postgraduate Institute of Medical Education and Research Chandigarh during year 2006 to 2008 after clearance from ethical committee. All pregnant women attending antenatal clinic were screened for anemia between 20-34 weeks of gestation. Screening was done in laboratory attached to the clinic. Iron deficiency anemia was diagnosed on the basis of automated red cell counts, peripheral blood smear, serum ferritin level and serum iron parameters. $\mathrm{Hb}$ electrophoresis and $\mathrm{HbA}_{2}$ quantitation was done when it was indicated, to exclude beta thalassemia trait. Two hundred women were included in the study who fulfills the inclusion criteria. Eligible criteria included were: hemoglobin level between 7-9g/dl, singleton live pregnancy, gestation age 20-34 weeks, microcytic hypochromic anemia, serum ferritin level $<15 \mathrm{ng} / \mathrm{ml}$.

Exclusion criteria included anemia other than iron deficiency, history of hematological disease, blood transfusion during current pregnancy, medical disorders, chronic blood loss, placenta previa. All eligible women were invited to gave informed consent were consecutively enrolled. A detailed history, physical and obstetric examination was done. All eligible women were randomly assigned to either intravenous or oral iron treatment. Opaque envelopes were consecutively numbered by means of a computer - generated randomization table. As each patient gave consent for the study, the next envelope was opened to assign the patients to either of the 2 groups.

Group A: Intravenous therapy.

\section{Group B: Oral iron therapy.}

Group A received intravenous iron sucrose. Dose was calculated by the following formula.

W x (target hemoglobin - Actual hemoglobin) x $0.24+$ $500 \mathrm{mg}$

Total dose rounded up to the nearest multiple of $100 \mathrm{mg}$.

$\mathrm{W}=$ Weight taken was pre-pregnancy weight or at the time of first visit.

Target hemoglobin-11g/L. Actual hemoglobin was the patient hemoglobin at the time of inclusion in the study.

Maximum dose administered in each infusion was 200 mg on alternate day. Women were kept in day care ward during and few hours after transfusion. Ten $\mathrm{ml}$ iron sucrose was diluted in $100 \mathrm{ml}$ of $0.9 \%$ sodium chloride, immediately prior to infusion and infused over 30-45 minutes. Test dose was not given.

Blood pressure was monitored before, during and after each infusion. All adverse events after each infusion were identified by physical examination and direct enquiry of each patient using standard forms encoded for adverse effects. Day 1 was the first day of intravenous therapy. Treatment was completed after administration of calculated dose. No further additional oral iron therapy was given in this group.

Group B received $100 \mathrm{mg}$ elemental iron three times a day throughout pregnancy. Patients were advised to take 
on an empty stomach, 2 hours before or after their meals and to record any side effects.

Both groups received $0.5 \mathrm{mg}$ folic acid per day.

In case of any adverse effects or intolerance in either of the groups, further treatment was given as per discretion of concerned physician.

\section{Monitoring and Follow-up}

Follow up was done according to our hospital protocol. Laboratory evaluation was performed at the time of inclusion in the study, Day 14 and Day 28 and then 4 weekly till delivery. Initial evaluation included; automated complete blood cell count including MCV, $\mathrm{MCH}, \mathrm{MCHC}$, and reticulocyte count, peripheral blood smear, iron studies. Subsequently complete blood count, reticulocyte count, iron studies were done at follow up visits. Two $\mathrm{ml}$ of blood sample was taken in EDTA for complete hemogram. For iron studies overnight fasting blood samples were collected. Five to $6 \mathrm{ml}$ blood in iron free tube was taken and serum was separated and stored for iron studies

Complete blood counts were measured by AutoAnalyzer; serum iron- binding capacity and serum ferritin were measured by chromogen assay, ferritin levels were determined by immunochemiluminescence.

Primary outcome was hemoglobin on day 14 and 28 after delivery, increase in reticulocyte count, increase in serum ferritin and sides effects and complications. Secondary outcome were percentage of patients who achieved desired hemoglobin $(11 \mathrm{~g} / \mathrm{dl})$ throughout pregnancy, pregnancy outcome, birth weight of baby and need of blood transfusion.

\section{Statistical analysis}

Using SPSS software on computer, paired and independent samples " $t$ " test was applied Hemoglobin measurements were analyzed by repeated- measures of analysis of variance (levene's test) with Huynh and Feldt corrections. Serum ferritin measurement across the time within each group was analyzed by two sample test with equal variance and multivariate tests including Pillai's trace, Wilks'lambda, Hotling's trace and Roy's largest root were applied. All significance tests were 2 -tailed, with an alpha level of 0.05 .

A Sample size calculation: A sample size analysis was performed before initiation of the study. The proposed study is a two arm repeated measure (base-line, $2^{\text {nd }}$ week, $4^{\text {th }}$ week and $8^{\text {th }}$ week) and therefore to see if the changes in measures from base-line to post intervention is statistically significant, the required sample size is calculated based on following formula.
$\mathrm{N}_{\mathrm{t}}=\left[\left\{2\left(\mathrm{Z}_{\alpha}+\mathrm{Z}_{\beta}\right)^{2}\right\}\{1+(\mathrm{n}-1) \rho\} \sigma_{\mathrm{d}}^{2}\right] /\left[\mu_{\mathrm{dc}}-\mu_{\mathrm{dt}}\right]^{2}$, where ' $\alpha$ ' the two sided level of significance is taken to be $5 \%$ and power of the study $(\beta)$ is taken as $90 \%$. It is assumed that mean $\left(\mu_{\mathrm{dc}}\right)$ of difference between base-line and second $(\mathrm{n})$ follow-up in control is 1.5 and mean $\left(\mu_{\mathrm{dt}}\right)$ of differences between base-line and second follow-up in treated group is 2.0. The common variance $\left(\sigma_{\mathrm{d}}^{2}\right)$ of differences is assumed to be 1 and correlation $(\rho)$ between base-line and follow-up measures is taken as 0.3 . The ratio of cases to control is set to be one and accordingly the sample size in each group is worked out to 89 .

\section{RESULTS}

Two hundred women were included in the study. At the end of study, we had complete data for 198 patients (100 patients in intravenous group and 98 patients in oral iron group). Two patients dropped out from oral group. One patient complained of itching after intake of oral iron sulphate and another had epigastric pain. At $8^{\text {th }}$ week all patients were delivered except 7 patients from I.V group and seventeen from oral group were left for follow up. Samples of 2 patients for serum ferritin and two for complete hemogram was not available at $8^{\text {th }}$ week from oral group and I.V group respectively.

All the patients in Group A received calculated total dose. The median dose was $800 \mathrm{mg}$ (range 600-1000 mg).

Demographic and clinical characteristics were similar in 2 groups (Table 1). Pregnancy related complications were comparable in both groups. One patient had thrombocytopenia, (2) Gestational hypertension and (2) had cholestasis of pregnancy in each group. Gestational hypertension had developed near term. One patients from oral group received platelet transfusion prior to cesarean section however one with thrombocytopenia in intravenous group had adequate platelet count to undergo vaginal delivery. None of the patients received blood transfusion in both the groups.

Notably there were significant differences in the hemoglobin levels at each measurement in both the groups shown in Fig.1. The rise in hemoglobin at subsequent week as compared to baseline was $1.7 \pm 0.92$ $\mathrm{gm} / \mathrm{dl}$ at second week, $2.80 \pm 1.03 \mathrm{gm} / \mathrm{dl}$ at $4^{\text {th }}$ week and $2.46 \pm 1.09 \mathrm{gm} / \mathrm{dl}$ at $8^{\text {th }}$ week in intravenous group which was $0.71 \pm 0.40 \mathrm{gm} / \mathrm{dl}$ at second week, $1.68 \pm 0.86 \mathrm{gm} / \mathrm{dl}$ at $4^{\text {th }}$ week, $1.84 \pm 0.77 \mathrm{gm} / \mathrm{dl}$ at $8^{\text {th }}$ week in oral group. $\mathrm{P}$ value was 0.000 at second and $4^{\text {th }}$ week. At 8 th week rise in hemoglobin was not significant $(\mathrm{P}=0.163)$ as it may be due to very small sample size.

The rise in serum ferritin was $155.33 \pm 57.4 \mathrm{ng} / \mathrm{ml}$ compared with $20.8 \pm 9.5 \mathrm{ng} / \mathrm{ml}$ at second week $(\mathrm{p}=0.000)$ and $70.85 \pm 46.25 \mathrm{ng} / \mathrm{ml}$ compared with $18.34 \pm 3.15$ $\mathrm{ng} / \mathrm{ml}$ at the fourth week $(\mathrm{p}=0.000)$ and at $8^{\text {th }}$ week $33.85 \pm$ $12.7 \mathrm{ng} / \mathrm{ml}$ compared with $24.2 \pm 4.6 \mathrm{ng} / \mathrm{ml}(\mathrm{p}=0.016)$ in intravenous and oral groups, respectively (Figure 2). 
Table 1: Baseline parameters.

\begin{tabular}{|llll|}
\hline Parameter & Group A $(\mathbf{A}=\mathbf{1 0 0})$ & Group B $(\mathbf{n = 9 8})$ & P \\
\hline Age $(\mathrm{yrs})$ & $25.53 \pm 2.99$ & $25.23 \pm 3.42$ & 0.518 \\
\hline Weight $(\mathrm{kg})$ & $53.66 \pm 5.86$ & $52.29 \pm 5.42$ & 0.083 \\
\hline Nulliparity & $65 \%$ & $73.4 \%$ & 0.196 \\
\hline Gestation at inclusion (weeks) & $29.68 \pm 1.25$ & $29.19 \pm 1.56$ & 0.017 \\
\hline Baseline $\mathrm{Hb}(\mathrm{g} / \mathrm{dl})$ & $8.0 \pm 0.79$ & $8.19 \pm 0.66$ & 0.068 \\
\hline Reticulocytes $(\%)$ & $1.84 \pm 0.84$ & $1.61 \pm 0.83$ & 0.074 \\
\hline S. Iron $(\mu \mathrm{g} / \mathrm{ml})$ & $44.91 \pm 27.5$ & $45.38 \pm 14.9$ & 0.881 \\
\hline TIBC $(\mu \mathrm{g} / \mathrm{ml})$ & $616.95 \pm 53.2$ & $604.9 \pm 38.59$ & 0.064 \\
\hline Transferrin saturation $(\%)$ & $8.75 \pm 6.6$ & $8.84 \pm 3.71$ & 0.90 \\
\hline Serum ferritin $(\mathrm{ng} / \mathrm{ml})$ & $6.25 \pm 2.60$ & $5.71 \pm 1.71$ & 0.130 \\
\hline
\end{tabular}

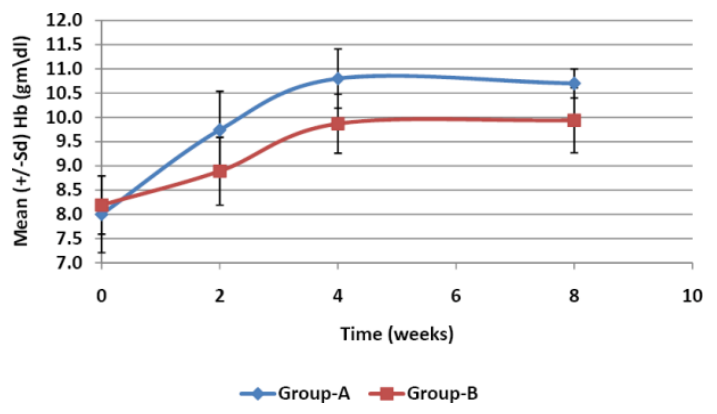

Figure 1: Comparison of $\mathrm{Hb}$ level at different time points in two groups of patients.

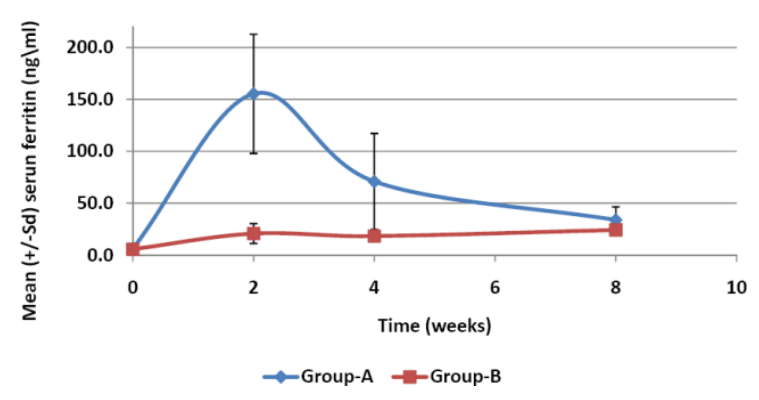

Figure 2: Comparison of serum ferritin level at different time points in two groups of patients.

At $4^{\text {th }}$ week $62 \%$ of patients in group A achieved target hemoglobin $(\geq 11 \mathrm{~g} / \mathrm{dl})$ whereas only $5.0 \%$ achieved in group B $(\mathrm{p}=0.00)$.

Only 6\% of patients from Group A had adverse events. Tachycardia (2), vomiting (2), change in taste (1), giddiness (1) and one developed thrombophlebitis. First patient had extreme pain due to thrombophlebitis. We had changed this practice of using I.V. cannula which has higher chances for displacement within the vein due to its long length. After that it was infused by scalp vein cannula with no complication of thrombophlebitis. All other symptoms were seen in those patients who accidently received fast infusion. It has seen that slower the infusion lesser will be the side effects.

Two patients from oral group dropped out due to side effects. Out of 98 patients $18(18.4 \%)$ patients had some side effects. Eight suffered from constipation, 5 complained of epigastric pain, 3 suffered from diarrhea and two experienced nausea. Most of these side effects seen during initial phase of treatment. Incidence of gastrointestinal related side effects were significantly higher in oral therapy ( $p=0.001$ ). There no significant difference in mode of delivery $(\mathrm{p}=0.055)$ and birth weight of baby $(\mathrm{p}=0.100)$.

\section{DISCUSSION}

The rapid rise in hemoglobin and iron stores is due to different pharmacokinetics of iron sucrose. In case of oral iron therapy, iron absorption is far below the iron requirement of an iron deficient pregnant woman. This is aggravated by the adverse effect of pregnancy on the gastrointestinal tract, which further reduces the bioavailability of iron and slow rise in hemoglobin.

Al- momen et al ${ }^{15}$ compared 52 pregnant patients treated with intravenous iron sucrose with 59 received $300 \mathrm{mg}$ of oral iron sulphate $300 \mathrm{mg}$ (60mg elemental iron)three times a day and found that intravenous treatment resulted in higher hemoglobin levels $128.5 \pm 6.6$ versus 
$111.4 \pm 12.4 \mathrm{~g} / \mathrm{l}$ in the oral iron group $(P<0.001)$ in a shorter period $6.9 \pm 1.8$ versus $14.9 \pm 3.1$ weeks in control group $(P \leq 0.001)$.In oral group $31.1 \%$ patients develop gastrointestinal symptoms and thirty percent had poor compliance. This study deviates from our study as baseline hemoglobin was less and target hemoglobin was $13 \mathrm{~g} / \mathrm{dl}$. The factor they used in the calculation was 0.3 , whereas we used 0.24 , in accord with the published data. In their study up to $30 \%$ patients developed gastrointestinal trouble whereas compliance with oral treatment was good in our study. Patient's information at inclusion regarding importance of oral iron and need of intravenous iron or blood transfusion as alternative certainly helps for the good compliance.

A trial by Bayoumeu et $\mathrm{al}^{16}$ involving 50 women observed rise in hemoglobin in i.v. group from $9.6 \pm 0.79$ to $11.11 \pm 1.3 \mathrm{~g} / \mathrm{dl}$ on day 30 from $9.7 \pm 0.5$ to $11 \pm 1.25 \mathrm{~g} / \mathrm{dl}$ on day 30 in the oral group which was not significant. Ferritin levels were higher in intravenous group, on day $30(P<0.0001)$ and at delivery $(P=0.01)$ which was significant but less than our study. Patient compliance in the oral group was reported excellent. In general we have used the similar method to that used by Bayoumeu et al. However there are differences between our study and those carried out by Bayoumeu et al that explain the different results. The baseline hemoglobin was higher, sample size was small and iron sucrose was given over 21 day in their study.

A study by Ragip et $\mathrm{al}^{17}$ included 90 iron deficient pregnant patients. The rise in hemoglobin at second week was $0.6 \mathrm{gm} / \mathrm{dl}$ as compared to $0.2 \mathrm{gm} / \mathrm{dl}(\mathrm{p}=.004)$ and, $4^{\text {th }}$ week $1.2 \mathrm{gm} / \mathrm{dl}$ as compared to $0.6 \mathrm{gm} / \mathrm{dl}(\mathrm{p}=.000)$ at in intravenous and oral group respectively. The rise serum ferritin was from $11 \pm 11 \mu \mathrm{g} / \mathrm{l}$ compared to $28 \pm 26 \mu \mathrm{g} / \mathrm{l}$ in the intravenous group $(P<0.001)$ at the fourth week and $18.1 \pm 11 \mu \mathrm{g} / \mathrm{l}$, compared with $23.7 \pm 13.8 \mu \mathrm{g} / 1 \quad(P=0.04)$ at birth in oral and intravenous group, respectively. In our study rise in hemoglobin and serum ferritin levels was higher at $2^{\text {nd }}$ and $4^{\text {th }}$ week than their study.

A clinical trial by PK Kochhar et $\mathrm{al}^{18}$ on 100 anemic antenatal women. Group $\mathrm{A}(\mathrm{n}=50)$ received $200 \mathrm{mg}$ tablets of ferrous sulphate, each containing $60 \mathrm{mg}$ elemental iron, three times a day for 4 weeks. In group B $(n=50)$, iron sucrose was given in divided doses of 200 $\mathrm{mg}$ each on alternate days by slow intravenous infusion. A statistically significant difference in increase of hemoglobin levels $(3.1 \mathrm{~g} / \mathrm{dL}$ in group A vs. $5.1 \mathrm{~g} / \mathrm{dL}$ in group i.v. group; $\mathrm{P}=0.002$ ) and ferritin levels between the two groups on day $30(\mathrm{P}=0.005)$. The adverse effects from iron treatment were mild but more prominent in group A. Neonatal outcome was comparable in the two groups. However, in our study rise in hemoglobin at 28 days was lesser then their study. This study deviates from our study due to less sample size.

Deeba Shafi, et $\mathrm{al}^{20}$ conducted a randomized controlled trial on 200 patients. Oral group received $200 \mathrm{mg}$ ferrous ascorbate and intravenous group received iron sucrose. The difference in hemoglobin values from baseline in the intravenous group was $1.72 \pm 0.484$ at 2 weeks, $2.18 \pm 0.865$ at 4 weeks, $2.89 \pm 0.5989$ at 6 weeks compared to oral iron, which is $0.5750 \pm 0.456$ at 2 weeks, $1.39 \pm 0.4402$ at 4 weeks, and $1.9 \pm 0.3020$ at 6 weeks. $P$ value was 0.000 which was clinically significant and showed that the hemoglobin levels were increased more in the intravenous group. At $2^{\text {nd }}$ and $4^{\text {th }}$ week rise in hemoglobin was comparable to our study. We have used similar formula to calculate dose of intravenous iron .This study deviates from our study as target hemoglobin was $12 \mathrm{gm} / \mathrm{dl}$ in their study. The rise in serum ferritin in intravenous group was $48.46 \pm$ $16.66 \mathrm{ng} / \mathrm{ml}$ at $2^{\text {nd }}$ week and $61.05 \pm 19.66 \mathrm{ng} / \mathrm{ml}$ at $4^{\text {th }}$ week which was $155.33 \pm 57.4 \mathrm{ng} / \mathrm{ml}$ at $2^{\text {nd }}$ week and $70.85 \pm 46.25 \mathrm{ng} / \mathrm{ml}$ at $4^{\text {th }}$ week of intravenous therapy in our study. Adverse events in the intravenous group were metallic taste in (five) patients, hot flushes (two), arthralgia (one), dizziness (one), and nausea (four). No drop out seen from oral group due to side effects. It is surprised to see as no patients developed thrombophlebitis in their study with good sample size.

Other studies have also not discussed how they have infused intravenous iron in their patients.

The review by Williams and Wheby ${ }^{21}$ notes that several studies considered anemia to be risk factor for low birth weight. Fetal birth weight was not different between groups in our study. No blood transfusion was required in either of the group.

New generation intravenous iron preparations are still lacking adequate trial for their use in pregnancy. Myers, B et $\mathrm{al}^{22}$ had analysed historical data of 92 pregnant patients who had received intravenous (IV) Ferric carboxymaltose and iron (III) hydroxide dextran. At four weeks, the total rise in $\mathrm{Hb}$ was $2.57 \mathrm{~g} / \mathrm{dL}$ Ferinject, $2.34 \mathrm{~g} / \mathrm{dL}$ Cosmofer. At six weeks the rise was $3.01 \mathrm{~g} / \mathrm{dL}$ and $3.2 \mathrm{~g} / \mathrm{dL}$ respectively. No serious adverse events were reported in either group. At $4^{\text {th }}$ week rise in $\mathrm{Hb}$ is less than our study. So till now we can safely rely on intravenous iron sucrose for its better safety profile. Our study has a good sample size. However we have not excluded the confounding factors like intake of iron prior to inclusion in the study. Other confounding factors like dietary habits, vegetarian or non- vegetarian were not asked in the history.

\section{CONCLUSION}

However this study had showed that intravenous iron is safe to use during pregnancy. It causes significant rise in hemoglobin and iron stores within short time which helps to cope up easily with excessive bleeding during delivery. Hence, it may help to reduce the need for blood transfusion and the associated risks.

Major advantages are safety, efficacy, good compliance, simple mode of administration in an outpatient setting 
and cost effectiveness because admission is not needed. It have extremely low incidence of side effects. Its use requires caution which can be reduced by giving it slowly under direct observation by the clinician.

\section{ACKNOWLEDGEMENTS}

The authors would like to thank Emcure Pharmaceuticals for supplying iron sucrose samples (Orofer $-\mathrm{S}$ ) free for poor patients also to $\mathrm{Mr} \mathrm{P}$. Venamail for statistical analysis.

\section{Funding: None}

Conflict of interest: None declared

Ethical approval: Taken

\section{REFERENCES}

1. World Health Organization. The World Health Report 2002: Reducing risks, promoting healthy life. World Health Organization, Geneva, 2002;1248.

2. World Health Organization. United Nations Children's Fund UNU. Iron deficiency anemia; Assessment, Prevention and Control; A guide for programme managers. World Health Organization, Geneva, 2001.

3. Geneva WHO 1DWNM 922. The Prevalence of Anemia in women.WHO1992;1-99.

4. Scholl TO, Hediger ML, Fischer RL, Shearer JW. Anemia vs. iron deficiency: increased risk of preterm delivery in a prospective study. Am J Clin Nutr. 1992;55:985-988.

5. Prevention and management of severe anemia in pregnancy. Report of a technical working group, Geneva, May 1991. World Health Organization, Geneva, 1993.

6. World Health Organization. Reduction of Maternal Mortality: A Joint WHO/ UNFPA/ UNICEF/ World Bank Statement. World Health Organization, Geneva, 1999.

7. Allen LH. Nutritional supplementation for the pregnant women. Clin Obstet Gynecol 1994;37:587595.

8. Centre for Disease Control.CDC criteria for anemia in children and childbearing aged women. MMWR Morb. Mortal. Wkly. Rep. 1989; 38:400-404.

9. Schrier S. Treatment of anemia due to iron deficiency. In: Rose B, editor. Up To Date. Wellesley (MA): Up To Date, 2004.

10. Beshara S Lundqvist H, Sundin J, Lubberink M, Tolmachev V, Valid S, et al. Pharmacokinetic and red cell utilization of iron (III) hydroxide -sucrose complex in anemic patients: a study using positron emission tomography. Br J Haematol 1999;104:296302.

11. Hillman RS, Henderson PA. Control of marrow production by the level of iron supply. J Clin Invest 1969;48:454-460.

12. Pritchard JA. Hemoglobin regeneration in severe iron deficiency anemia; response to orally and parenterally administered iron preparations. JAMA 1966; 195:717-720.

13. Van wyck DB, Cavallo G, Spinowitz BS, Adhikarla R, Gagnon S, Charytan C, et al. Safety and efficacy of iron sucrose in patients sensitive to iron dextran : North American clinical trial. Am J Kidney Dis 2000;36:88-97

14. Faich G, Strobos J. sodium ferric gluconate complex in sucrose: safer intravenous iron therapy than iron dextrans. Am J Obstet Gynecol 1999;33 467-470.

15. al-Momen AK, al-Meshari A, al Nuaim L, Saddique A, Abotalib Z, Khashogji T,et al. Intravenous iron sucrose complex in the treatment of irons deficiency anemia during pregnancy. Eur J Obstet Gynecol Reprod Biol 1996;69:121-124.

16. Bayoumeu F, Subiran-Buisset C, Baka NE, Legagneur H, Monnier-Barbarino P, Laxenaire MC. Iron therapy in iron deficiency anemia in pregnancy: intravenous route versus oral route. Am J Obstet Gynecol 2002;186:518-522.

17. Ragip A. Al, Eylem Unlubilgin, Omer Kandemir, Serdar Yalvac, Leyla Cakir, Ali Haberal. Intravenous versus oral iron for treatment of Anemia in pregnancy. ACOG 2005;106:1335-1340.

18. Kochhar PK, Kundal A, Ghosh P. Intravenous iron sucrose versus oral iron in treatment of iron deficiency anemia in pregnancy: a randomized clinical trial. J Obstet Gynaecol Res 2013 Feb;39(2):504-10.

19. Deeba Shafi, Shekhar V. Purandare, and A. V. Sathe. Iron Deficiency Anemia in Pregnancy: Intravenous versus Oral Route. J Obstet Gynaecol India 2012 June;62(3):317-321.

20. Reveiz L, Gyte GML, Cuervo LG. Treatments for iron-deficiency anaemia in pregnancy. Cochrane Database of Systematic Reviews 2010; Issue 3.

21. Williams MD, Wheby MS. Anemia in pregnancy. Med Clin North Am 1992;76:631-47.

22. Myers, B, Myers O, Moore JS. Comparative efficacy and safety of intravenous ferric carboxymaltose (Ferinject) and iron (III) hydroxide dextran (Cosmofer) in pregnancy Obstetric Medicine Sep2012;5(3):105.

DOI: $10.5455 / 2320-1770.1 j \mathrm{rcog} 20131211$

Cite this article as: Dubey S, Suri V, Aggarawal

$\mathrm{N}$, Das R. Is it safe to use intravenous iron sucrose during pregnancy? A randomized controlled trial. Int J Reprod Contracept Obstet Gynecol 2013;2:544-9. 